\title{
Selective Laser Trabeculoplasty as a Replacement Therapy in Open Angle Glaucoma: A 3-Year Follow-Up Review
}

\author{
Gonen Baser ${ }^{1 *}$, Eyyup Karahan ${ }^{2}$ \\ ${ }^{1}$ Özel Medifema Hospital, Turkey \\ ${ }^{2}$ Van Education and Training Hospital, Department of Ophthalmology, Turkey \\ *Corresponding author: Gonen Baser, Özel Medifema Hospital, Eye Clinic, 1429 Sok. No: 1/3 Alsancak-Izmir/ Turkey \\ Submission: 海January 05, 2018; Published: 淟January 22, 2018
}

\begin{abstract}
The aim of this study was to investigate the long-term effect of selective laser trabeculoplasty in open angle glaucoma patients as a replacement for medical therapy. 64 eyes of 64 primary open angle glaucoma (POAG) patients under therapy with glaucoma drugs and controlled Intra Ocular Pressure (IOP) were reviewed for 36 months. 360o selective laser therapy (SLT) sessions were performed in two sessions and the medical therapy was stopped. The patients were controlled and evaluated postoperatively 1, 3, 6, 12, 24 and 36 months after surgery for glaucoma progression. In 36 (56.3\%) of the 64 patients SLT was successful and there was no need to medical treatment at $36^{\text {th }}$ month. In 28 patients $(43.7 \%)$ medical treatment was started due to IOP rising. In Logistic regression analysis baseline IOP was found to be significantly effective on success rate of SLT (R2: 0.718, $\mathrm{p}<0.001$ ).
\end{abstract}

The success rate of SLT on medicated POAG patients with controlled IOP is high. SLT could be considered as a serious alternative in patients who do not have advanced glaucoma, and have ocular surface problems.

Keywords: Primary open angle glaucoma; Selective laser trabeculoplasty; Ocular surface toxicity

\section{Introduction}

Glaucoma is a progressive optic neuropathy which results with vision loss if left untreated [1]. Numerous clinical trials demonstrated that the only evidence-based treatment paradigm for glaucoma focuses on reducing Intra Ocular Pressure (IOP), which, if left untreated, has been associated with disease progression [2]. However, medical glaucoma therapy lasts for a lifetime and can reduce the life comfort of the patients due to the serious local and systemic side effects of the drugs. Topical $\beta$-blockers have been associated with systemic cardiac and respiratory adverse effects, which may limit their use in some patients [3]. On the other hand, Prosta Glandine Analogs (PGA) can causes upper eyelid crease, ptosis, periocular hyperpigmentation or eyelash elongation $[4,5]$. Especially important side effects caused by the preservant chemicals such as benzalchonium chloride or Poly Quad (PQ) on the ocular surface, which are widely used in glaucoma drops [6,7].

SLT is a method of non-invasive IOP reduction, which is first reported by Latina. The device is a Q-switched, frequency-doubled $\mathrm{Nd}$ :YAG laser that is melanosome-specific and is widely used to lower IOP in patients with open-angle glaucoma or ocular hypertension. SLT works by selective targeting of pigmented trabecular meshwork with minimal structural damage [8]. This makes SLT a repeatable therapy with minimal side effects.
Current identification of patients with glaucoma is not optimal because a large number of prevalent cases are undiagnosed, or patients with ocular hypertension are misdiagnosed as glaucoma and are under treatment. This leads to unnecessary life-time therapy costs and side effects of the therapeutics and a number of misdiagnosed patients $[9,10]$.

There are two main goals in the treatment of diseases, including glaucoma. The first goal is an effective treatment, which means preserving the sight and prevent the visual field losses in glaucoma. The second goal is to achieve these results with minimal side effects. To evaluate this, we planned this study. We performed SLT in patients with diagnosed glaucoma under medical therapy and normal IOP values and ceased the medical therapy. The patients were followed-up for three years. There are some studies with similar design, however, to our knowledge our study has the longest follow-up time.

\section{Material and Methods}

This study is a retrospective chart review of patients who were diagnosed as POAG before and currently medicated with topical antiglaucoma therapy. The patients who felt uncomfortable with topical anti-glaucoma drugs and an IOP under $20 \mathrm{~mm} \mathrm{Hg}$, were offered SLT as an alternative replacement therapy under strict 
control. The patients were informed that the possibility exists that SLT could not be efficient, and if we would not achieve the target IOP, the topical therapy will be started again. SLT was performed in these patients to cease the therapy. In the patients who did not prefer SLT, the medical therapy was continued, and we did not try to convince them to replace their medical therapy with SLT. The study contains patients who were treated at the Sifa University Hospital Eye Clinic between August 2011 and August 2012.

Informed patient consent were obtained from all patients that their medical data could be used in scientific studies without personal identification. All procedures performed in this study were in accordance with the ethical standards of the institutional and/or national research committee and with the 1964 Helsinki declaration and its later amendments or comparable ethical standards. For this type of study, no formal consent is required.

All patients underwent a full ocular examination, including bestcorrected visual acuity, slit-lamp evaluation, Goldmann applanation tonometry (this study used two initial IOP measures for each patient to reduce the effect of diurnal variation and improve accuracy), corneal pachymetry, gonioscopy, dilated fundoscopy, visual field testing and imaging as appropriate. All patients were under the treatment of one or fixed antiglaucoma drops (beta blockers, prostaglandin analogues and carbonic anhydrase inhibitor or alpha adrenergic agonists). Only the right eyes were evaluated.

Patients with any pre-existing corneal pathology or scars, pseudoexfoliative glaucoma, juvenile glaucoma, or any secondary glaucoma, previous ALT or SLT treatment, defaulted follow-up, any previous intraocular surgery, such as cataract, retinal detachment, glaucoma surgery and any previous uveitis or intraocular inflammation and ocular hypertension were excluded.

\section{SLT Treatment Technique}

In the present study, the SLT treatment was performed over $180^{\circ}$ of the Trabecular Meshwork (TM) with the SLT Lightmed Combi Laser $®$ and approximately 50 spots were applied to the TM. The initial energy of the laser was $0.8 \mathrm{~mJ}$. The energy was increased or decreased until bubble formation appeared. The energy used in the present study was between 0.5 and $1.0 \mathrm{~mJ}$. No more laser energy was necessary to achieve the desired bubble formation. No medication is given to any patient who were treated with SLT, unless

\section{Results}

Table 1: Mean IOP levels at baseline examination, first, $3^{\text {th }}, 6^{\text {th }}, 12^{\text {th }}, 24^{\text {th }}$ and $36^{\text {th }}$ months.

\begin{tabular}{|c|c|c|c|c|c|}
\hline & N & Minimum & Maximum & Mean & 15,9375 \\
\hline Baseline & 64 & 11,00 & 19,00 & 14,8594 & 2,40947 \\
\hline $1^{\text {th }}$ month & 64 & 12,00 & 20,00 & 15,5938 & 2,04488 \\
\hline $3^{\text {th }}$ month & 64 & 12,00 & 20,00 & 16,9531 & 3,68795 \\
\hline $6^{\text {th }}$ month & 64 & 12,00 & 27,00 & 17,3594 & 2,92427 \\
\hline $12^{\text {th }}$ month & 64 & 13,00 & 26,00 & 17,8750 & 2,98940 \\
\hline $24^{\text {th }}$ month & 64 & 14,00 & 25,00 & 16,9375 & 1,69851 \\
\hline $36^{\text {th }}$ month & 64 & 14,00 & 23,00 & & \\
\hline
\end{tabular}


64 eyes of 64 patients are enrolled into the study. Mean age was $50.8 \pm 7.2$ years (range: 39 to 66 years). Thirty patients ( $46.9 \%$ ) were male, 34 patients were female (53.1\%). Baseline IOP was $15.9 \pm 2.4$ (range: 11 to $19 \mathrm{mmHg}$ ). Mean IOP levels at baseline examination, first, 3th, 6th,12th, 24th and 36 th months are shown in (Table 1).

In $36(56.3 \%)$ of the 64 patients SLT was successful and there was no need to medical treatment at 36th month. However, in 28 patients (43.7\%) medical treatment was started due to IOP rising. In patients with successful SLT mean baseline IOP was 14.4 \pm 2.1 , in failured patients mean baseline IOP was $17.9 \pm 0.8(\mathrm{p}<0.001)$. Four patients needed 6 months later (6.25\%), four patients 12 months $(6.25 \%)$ and $20(31.25 \%)$ patients two years later after SLT further glaucoma medication.

In logistic regression analysis baseline IOP was found to be significantly effective on success rate of SLT (R2: $0.718, p<0.001)$. In patients with successful SLT mean baseline IOP was $14.4 \pm 2.1$, in failed patients mean baseline IOP was $17.9 \pm 0.8(\mathrm{p}<0.001)$.

\section{Discussion}

The present study contributes to the idea that SLT could be considered as an alternative therapy for early stage POAG. In our patients, SLT has given the facility to follow-up them without any medication for a time of three years.

There are two issues of glaucoma management, which has to be taken into consideration. The first one is to maintain the visual function throughout the life, the second is to protect the ocular surface from the side-effects of the antiglaucoma therapy. These both issues are directly related to the quality of life of the glaucoma patients. Glaucoma is a progressive disorder that requires chronic daily medication; however, up to $70 \%$ of patients are nonadherent to their medications within the first year. Hyperemia, pain, burning, and ocular discomfort are common causes of patient nonadherence [11]. On the other hand, patient-related, medicationrelated, physician-related and environmental, psychological and socioeconomical factors has been reported as important reasons for therapy adherence [12,13].

When we reviewed our results, we observed that 6 patients needed medical therapy after SLT treatment before one year. Although it has been reported that higher IOP prior SLT has a positive influence on the effect of SLT [14], this was not observed in our patients. After the first control, the drop in IOP was similar in all patients. But the patients we needed to treat after SLT had a higher baseline IOP than the no medication needed patients. This might be due to the difference of severity of the patients and/or the minimal tissue effect of the SLT on TM. On the majority of the patients the IOP could be kept under limits for two years and a little more than the half are still do not need further antiglaucoma drugs. It is well known that the therapeutic effect of SLT is temporary [15]. But in overall, the patients could be kept in safety levels for a relative long time. Thus, they were protected from the systemic and local side effects from the drugs.

SLT as a replacement for antiglaucoma drugs has been reported before. Francis et al. and Zhang et al. recommended in their studies SLT as a reliable alternative therapy. However they reported one year and 6-9 month results, respectively $[16,17]$. They reported a success rate over $85 \%$ either in short term. These results are similar to ours in the mentioned period. Nevertheless, the effect of SLT decreased in our study after one year. A similar effect of SLT as an adjuvant therapy in medicated glaucoma patients has been achieved by Lee et al. [18]. We observed still an IOP under the critic level for a time of one year further. The most patients we need to cure with medical therapy were two years after SLT. The question to ask here is, should we repeat the SLT. When we evaluated the status of the patients, we decided to go on with medical therapy. This could be another aspect in glaucoma therapy, and our opinion is, this should be investigated in prospective long-term studies.

Our study has its limitations. The first one is the retrospective design. Some drugs are in relevance of SLT success. As reported before, while Prosta Glandine Analogs (PGA) has a lesser effective influence on the outcomes of SLT [19], Carbonic Anhydrase Inhibitors (CAI) were associated with greater SLT success [20]. Prostaglandin eye drops may be associated with SLT failure because SLT works by increasing the metalloproteinase and macrophages in the trabecular meshwork; thus, the use of prostaglandin analogs can theoretically lead to hypoperfusion of the trabecular meshwork by increased uveoscleral outflow or suppression of metalloproteinases $[19,20]$. Unfortunately in our study all of the patients were used similar groups of drugs and the number of the patients was insufficient to make a classification to analyse the drug effect on them. There are some studies with similar design, however, to our knowledge our study has the longest follow-up time1

In conclusion, our study demonstrates that SLT keeps the IOP in safety levels in a proportion more than $50 \%$ in patients who were treated with antiglaucoma drugs before. We believe that, this is a satisfactory result. To our knowledge, this is the first study in which the long-term results of SLT as a replacement therapy has been investigated. SLT could be considered as a serious alternative in patients, who have a stable course of their IOP with antiglaucoma drugs, especially if they have complaints due to their medication. Further investigations are necessary to determine the benefit or disadvantages of SLT in various glaucoma indications.

\section{Acknowledgment}

All authors certify that they have no affiliations with or involvement in any organization or entity with any financial interest (such as honoraria; educational grants; participation in speakers bureaus; membership, employment, consultations, stock ownership, or other equity interest; and expert testimony or patentlicensing arrangements), or non-financial interest (such as personal or professional relationships, affiliations, knowledge or beliefs) in the subject matter or materials discussed in this manuscript.

\section{References}

1. Casson RJ, Chidlow G, Wood JP, Crowston JG, Goldberg I (2012) Definition of glaucoma: clinical and experimental concepts. Clin Experiment Ophthalmol. 40(4): 341-349. 
2. Heijl A, Leske MC, Bengtsson B, Bengtsson B, Hussein M (2003) Early Manifest Glaucoma Trial Group. Measuring visual field progression in the Early Manifest Glaucoma Trial. Acta Ophthalmol Scand 81(3): 286293.

3. Uusitalo H, Kahonen M, Ropo A, Maenpaa J, Bjarnhall G, et al. (2006) Improved systemic safety and risk-benefit ratio of topical $0.1 \%$ timolol hydrogel compared with $0.5 \%$ timolol aqueous solution in the treatment of glaucoma. Graefes Arch Clin Exp Ophthalmol. 244(11): 1491-1496.

4. Karslioglu MZ, Hosal MB, Tekeli O (2015) Periocular changes in topical bimatoprost and latanoprost use. Turk J Med Sci 45(4): 925-930.

5. Nakakura S, Yamamoto M, Terao E, Nagatomi N, Matsuo N, et al. (2014) Prostaglandin-associated periorbitopathy in latanoprost users. Clin Ophthalmol 30(9): 51-56.

6. Anwar Z, Wellik SR, Galor A (2013) Glaucoma therapy and ocular surface disease: current literature and recommendations. Glaucoma therapy and ocular surface disease: current literature and recommendations. Curr Opin Ophthalmol 24(2): 136-143.

7. Labbé A, Pauly A, Liang H, Brignole-Baudouin F, Martin C, et al. (2006) Comparison of toxicological profiles of benzalkonium chloride and polyquaternium-1: an experimental study. J Ocul Pharmacol Ther 22(4): 267-278.

8. Latina MA, Park C (1995) Selective targeting of trabecular meshwork cells: in vitro studies of pulsed and CW laser interactions [Abstract]. Exp Eye Res 60(4): 359-371.

9. Wong EY, Keeffe JE, Rait JL, Vu HT, Le A, et al. (2004) Detection of undiagnosed glaucoma by eye health professionals. Ophthalmology 111(8): 1508-1514.

10. Topouzis F, Coleman AL, Harris A, Koskosas A, Founti P, et al. (2008) Factors associated with undiagnosed open-angle glaucoma: the Thessaloniki Eye Study. Am J Ophthalmol 145(2): 327-335.

11. Reardon G, Kotak S, Schwartz GF (2011) Objective assessment of compliance and persistence among patients treated for glaucoma and ocular hypertension: a systematic review. Patient Prefer Adherence 5 441-463.
12. Cohen Castel O, Keinan-Boker L, Geyer O, Milman U, Karkabi K (2014) Factors associated with adherence to glaucoma pharmacotherapy in the primary care setting. Fam Pract 31(4): 453-461.

13. Hong S, Kang SY, Yoon JU, Kang U, Seong GJ, et al. (2010) Drug attitude and adherence to anti-glaucoma medication. Yonsei Med J 51(2): 261269.

14. Lee JW, Liu CC, Chan JC, Lai JS (2014) Predictors of success in selective laser trabeculoplasty for chinese open-angle glaucoma. J Glaucoma 23(5): 321-325.

15. Hodge WG, Damji KF, Rock W, Buhrmann R, Bovell AM, et al. (2005) Baseline IOP predicts selective laser trabeculoplasty success at 1 year post-treatment: results from a randomised clinical trial [Abstract]. Br J Ophthalmol 89(9): 1157-1160

16. Francis BA, Ianchulev T, Schofield JK, Minckler DS (2005) Selective laser trabeculoplasty as a replacement for medical therapy in open-angle glaucoma. Am J Ophthalmol 140(3): 524-525.

17. Zhang H, Yang Y, Xu J, Yu M (2015) A prospective randomized study of selective laser trabeculoplasty (SLT) as a replacement for medical therapy in primary open-angle glaucoma [Abstract].[Article in Chinese] Zhonghua Yan Ke Za Zhi 51(2): 109-114.

18. Lee JW, Chan CW, Wong MO, Chan JCh, Li Q, et al. (2014) A randomized control trial to evaluate the effect of adjuvant selective laser trabeculoplasty versus medication alone in primary open-angle glaucoma: preliminary results. Clin Ophthalmol 8: 1987-1992.

19. Song J, Lee PP, Epstein DL, Stinnett SS, Herndon Jr LW, et al. (2005) High failure rate associated with 180 degrees selective laser trabeculoplasty. J Glaucoma 14(5): 400-408.

20. Kara N, Altan C, Satana B, Altinkaynak H, Bozkurt E, et al. (2011) Comparison of selective laser trabeculoplasty success in patients treated with either prostaglandin or timolol/dorzolamide fixed combination. J Ocul Pharmacol Ther 27(4): 339-342. 